\title{
Assessment of the genotoxicity of water and soil in the places of storage of reserves of old pesticides by Allium-test
}

\author{
Oksana Cherednichenko*, Serikbay Nuraliev, Bakytzhan Bekmanov, Anastassiya Pilugina, \\ Leila Dzhansugurova, and Gulnara Baigushikova
}

Institute of General Genetics and Cytology, Almaty, Kazakhstan

\begin{abstract}
Pesticides and persistent organic pollutants (POPs) are a serious environmental problem for almost all countries of the world. The toxic and mutagenic activity of samples of natural water and water extracts of soils collected near the storage sites of old and prohibited pesticides located in the villages of Kyzylkairat, Amangeldy, Beskainar, Belbulak, Enbekshi. Territories of comparison - Basshi village (Altyn Emel National Park) and near farmland, where pesticides were used in the past (Taukaraturk village, Almaty region) was investigated. Allium cepa L. was used as a biological test system. The mitotic activity and the frequency of disturbances at different stages of mitosis in onion root meristem were evaluated. Chemical analysis showed that in all soil samples the total content of 24 POPsPesticides exceeds the maximum permissible concentration (MPC). It was established that the level of mitotic activity of Allium cepa cells in all samples was slightly reduced compared with the control. In soil samples, the frequency of micronuclei in interphase cells $(0.22-3.25 \%)$ is higher than in water samples $(0.36-0.99 \%)$ (control - $0.41 \%)$. The revealed increased level of cytogenetic disorders correlates with the total content of organochlorine pesticides.
\end{abstract}

\section{Introduction}

The impact that is the pesticides have on the environment is acute and the issue of major concern for many countries. The Republic of Kazakhstan faces the stockpiling due to the large amount of obsolete pesticides which had not yet been disposed since the Soviet times. Still being stored in leaky conditions of the dilapidated warehouses they pollute the surrounding area and water supplies [1].

Persistent organic pesticides are characterized by the following features: they remain in the environment for a long time until their full decomposition; they transmitted over long distances, even to areas far from thousands of kilometers from their emission sources; they are accumulated in the tissues of all living organisms penetrating with food, drinking water or atmospheric air; they poison human and animals, causing wide spectrum of toxic disturbances; they have a mutagenic, teratogenic or carcinogenic effect; they can also

*Corresponding author: cherogen70@mail.ru 
concentrate as they move along the trophic chain: "soil - plant - animal - human" locally increasing the accumulation level in the body.

One of the most promising methods for determining the total effect of toxicants on natural environment objects of natural inhabitants is testing of the state of bioindicator organisms, which can be microorganisms, fungi, endemic species of plants and animals. The main condition for using a living organism as an object of bioindication is the possibility of fast fixation of a certain type of disturbances caused by genotoxic agents of the habitat. At the same time, it is important that methods for assessing the state of environmental objects using biotesting methods are rapid and do not require large financial costs. Allium cepa was applied as a biological indication, it is standardized, sensitive and officially recognized method which has been in use widely for more than four decades to assess the quality/pollution of water and water supplies, as well as the ground and the state of environment resulting from the harmful effects from different kinds of pollutants including pesticides [2] (The Allium root tip chromosome aberration assay has been adopted by the International Program on Plant Bioassay (IPPB), for monitoring or testing environmental pollutants [3]).

In this regard, it was necessary to assess the toxic and mutagenic activity of natural water and soil samples collected near the storage sites of old and prohibited pesticides using the Allium cepa model test system. This study is part of a bioecological analysis of long-term environmental pollution in Almaty region by persistent organic pollutants to assess the risk to public health.

\section{Materials and methods}

The search was implemented for toxicant mutagenic activity of ambient water samples along with the soil-water extracts collected from around the 5 sites of demolished warehouses which are located in the Almaty region, namely the villages Kyzylkairat, Amangeldy, Beskainar, Belbulak and Enbekshias well as from the 2 intercomparison fields: farm lands close to the countryside Taukaraturyk, where pesticides had been used time ago and National Park Altyn-Emel in Basshi village as a control-point area. A clean water was used as an internal control measure.

The sampling of water was carried out in accordance with GOST 17.1.5.05-85 "General requirements for the sampling of surface and sea water" in the spring. Sampling of soil samples was carried out according to the procedure, which meets the requirements of GOST 14.4.4.02.-84., GOST-29269-91, by the method called "envelope" from soil horizons 1 (from 0 to $5 \mathrm{~cm}$ deep) and 2 (from 5 to $25 \mathrm{~cm}$ deep). For the chemical analysis and evaluation of the genotoxic potential, water and soil samples were taken, each weighing not less than $1 \mathrm{~kg}$. Samples of water were taken in 11 plastic bottle.

Water extracts of soils were prepared as follows: soil samples $(30 \mathrm{~g})$ were poured into $150 \mathrm{~cm} 3$ of distilled water, stirred for 3 minutes on a mixer and left for 5 minutes to settle (GOST 26423-85).

Conducting quantitative analysis of environmental samples for pesticides and their metabolites ( 24 pesticides) was carried out with sample preparation of water from natural reservoir sand soil in accordance with GOST 29269-91 Soils. General requirements for analysis. Gas chromatography and mass spectrometry were used to determine pesticides and their metabolites in samples of soil and water.

To study cytogenetic abnormalities using the Allium cepa test object, onion seeds were germinated in Petri dishes at a temperature of $24^{\circ} \mathrm{C}$ for 72 hours in the test sample. The squash technique for onion root as described [4] was used for the cell division stages investigation. Cells samples were taken from root meristems containing actively growing cells. The mitotic index (MI) and the frequency of disorders in different stages of mitosis were defined in onion root meristem. 


\section{Results and discussion}

When analysing the POPs quantity in natural water around the former pesticides warehouses it was revealed that all investigated samples contain highly toxic metabolite of DDT - DDE. The MPC in water for DDE is $2 \mathrm{mg} / \mathrm{dm}^{3}$. The residual amount of the metabolite DDE varied in natural water from 2.4 to $5.4 \mathrm{mg} / \mathrm{dm}^{3}$. It is established that samples of natural water also contain the metabolite 2.4 DDD and 4.4 DDD. Also in some samples, endosulfansulfate in concentration $0.184-1.33 \mu \mathrm{g} / \mathrm{dm}^{3}$, dibutylendan $0.325-1.788 \mu \mathrm{g} / \mathrm{dm}^{3}$, methoxychlor 0.12 $\mu \mathrm{g} / \mathrm{dm}^{3}$, hexabromobenzene $0.287 \mu \mathrm{g} / \mathrm{dm}^{3}$, deldrin $0.0625-0.1213 \mu \mathrm{g} / \mathrm{dm}^{3}$, heptachlorepoxide $0.063 \mu \mathrm{g} / \mathrm{dm}^{3}$, chlordan $0.03 \mu \mathrm{g} / \mathrm{dm}^{3}, 2.4$ DDD $0.538 \mu \mathrm{g} / \mathrm{dm}^{3}$ and 4.4 DDD $0.21-0.365 \mu \mathrm{g} / \mathrm{dm}^{3}$ were present.

In the study of soil samples, it has been found that soil around the former warehouses has a multicomponent pollution, i.e. polluted by pesticides and heavy metals. The strongest pollutants of the soil are DDT $(0.1624-21.2 \mathrm{mg} / \mathrm{kg})$ and DDE $(0.2372-2209 \mathrm{mg} / \mathrm{kg})$. Also collected soil samples contained $\beta-\mathrm{HCH}$, aldrin, dibutilendan, endosulfansulfate, geptahlorepoksid, deldrin, endrin, chlorobenzilate.

The total content of pesticides in specimens is shown in Fig. 1.

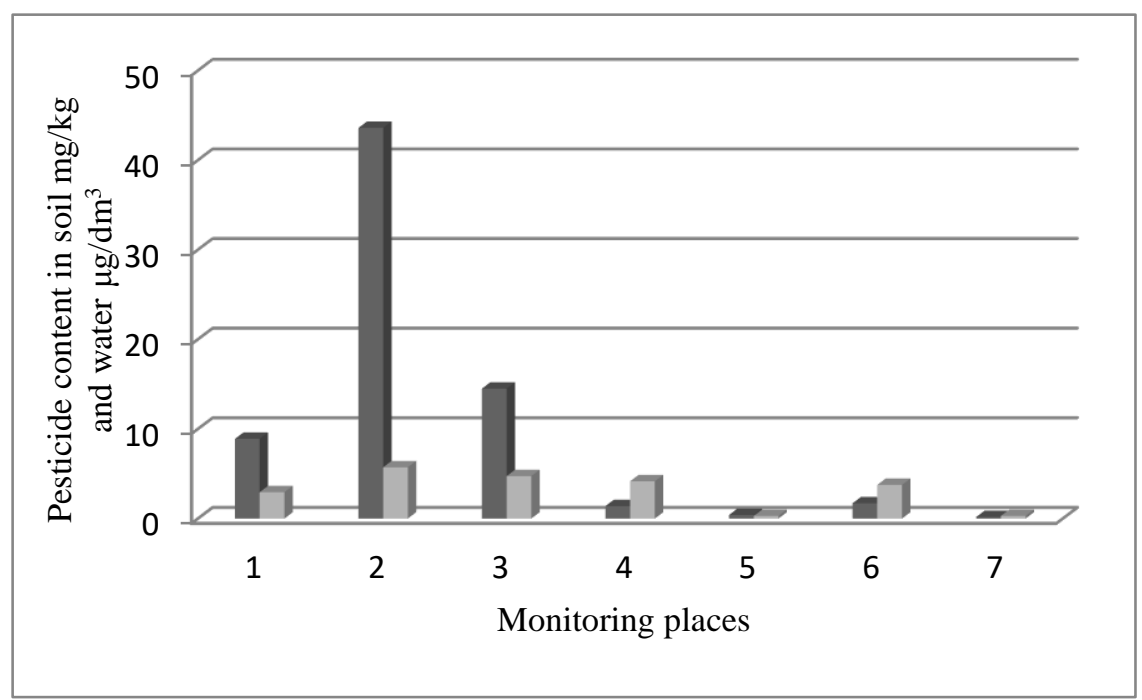

Fig. 1. The total content of organochlorine pesticides in the studied soil and water samples.

1 - Beskainar, 2 - Kyzylkairat, 3 - Amangeldy, 4 - Belbulak, 5 - Enbekshi, 6 - Taukaraturyk, 7 Basshi

It is established that in all samples the total amount of pesticides in the soil exceeds the MPC. The soil most polluted by pesticides was taken from the territories of former pesticide storage facilities located in the villages Kyzylkairat, Amangeldy and Beskainar. The concentration of pesticides in the soil exceeded the MPC from 60 to 120 MPC. In the village Taukaraturyk, where there are no official data on the location of the former pesticide storage facilities, the concentration of POPs pesticides in the soil exceeded the MAC up to 17 times. The concentration of pesticide POPs in soil samples taken from the territories of former pesticide storage facilities located in the villages of Belbulak and Amangeldy (the burial place of pesticides) also exceeded the MPC in the soil from 9 to 15 times. It should be noted that the ratio of DDT and its derivatives makes it possible to approximately estimate the time of appearance and decomposition of residual concentrations of pesticide contained in soils. 
Thus, the ratio (DDE + DDD) / DDT $>1$ indicates the "old" use of DDT and its active transformation by microorganisms.

The results obtained from cytogenetic analysis of the apical meristem through Allium test for disorders in interphase cells and during different stages of cell division are presented in table 1. It was identified that the mitotic values derived from Allium test cells in all samples were slightly decreased compared with the control meanings.

Table 1. The frequency of cytogenetic disorders in assessing the genotoxicity of soil and natural water samples using the Allium test.

\begin{tabular}{|c|c|c|c|c|c|c|c|}
\hline Variant & $\begin{array}{c}\text { Cells } \\
\text { viewed }\end{array}$ & Interphase & Prophase & Metaphase & Anaphase & Telophase & $\begin{array}{c}\text { Mitotic } \\
\text { index }\end{array}$ \\
\hline \multicolumn{8}{|c|}{ Beskainar } \\
\hline Water & 3028 & 0.71 & 1.48 & 24.49 & 9.64 & 1.89 & 15.87 \\
\hline Soil & 3041 & $1.38^{*}$ & - & 6.48 & 4.82 & - & 12.96 \\
\hline \multicolumn{8}{|c|}{ Kyzylkairat } \\
\hline Water & 3546 & 0.99 & 0.32 & 22.45 & 14.41 & 1.72 & 17.38 \\
\hline Soil & 3103 & $3.57^{*}$ & & 10.17 & 3.60 & - & 15.06 \\
\hline \multicolumn{8}{|c|}{ Amangeldy } \\
\hline Water & 3047 & 0.79 & 0,86 & 15.46 & 21.98 & 1.89 & 16.80 \\
\hline Soil & 1500 & 0.87 & - & 3.22 & 10.00 & - & 12.55 \\
\hline \multicolumn{8}{|c|}{ Belbulak } \\
\hline Water & 1500 & 0.92 & - & - & 11.10 & 11.10 & 14.40 \\
\hline Soil & 1520 & 0.93 & - & 4.50 & 9.50 & - & 15.80 \\
\hline \multicolumn{8}{|c|}{ Enbekshi } \\
\hline Water & 3532 & 0.36 & 0.39 & 19.19 & 9.09 & - & 13.78 \\
\hline Soil & 1500 & 0.22 & - & 4.54 & 9.23 & - & 14.80 \\
\hline \multicolumn{8}{|c|}{ Taukaraturyk } \\
\hline Water & 1668 & 0.72 & 0.28 & 13.11 & 12.82 & 1.61 & 19.08 \\
\hline Soil & 1530 & $2.59^{*}$ & 3.33 & 18.70 & 12.80 & & 12.80 \\
\hline \multicolumn{8}{|c|}{ Basshi } \\
\hline Water & 1500 & 0.45 & - & - & - & - & 12.40 \\
\hline Soil & 1500 & 0.46 & - & 2.00 & 6.67 & - & 15.00 \\
\hline Distilled water & 1522 & 0.41 & - & 5.88 & 4.17 & - & 19.00 \\
\hline
\end{tabular}

It has been detected that in soil samples the frequency of micronuclei (MN) in interphase cells $(0.22-3.57 \%)$ is higher than that in water samples $(0.36-0.99 \%)$ and in some cases it significantly exceeds the reference level. The greatest number of violations was recorded at the key stages of cell division - metaphase and anaphase. Analysis on water samples revealed significantly more violations in different stages of mitosis, suggesting the presence of chemical substances with mitotic modifying and genotoxic effects in water. A particularly high level of disturbances at these stages was revealed when analysing water from the villages of Beskaynar, Kyzylkairat and Amangeldy. According to total estimates, the most polluted soil and water were reported from Kyzylkairat and Beskainar village. It is worthwhile noting that in township Taukaraturyk, where pesticides have not been used for more than 20 years the level of their residues in the soil significantly increases the frequency of cytogenetic disturbances in the interphase and prophase of cell division.

It was evaluated that disorders in interphase nuclei and in prophase were represented by micronuclei, in metaphase - as micronuclei, dropped chromosomes and C-metaphases, in anaphase - chromosome bridges and lagging chromosomes, in telophase - chromosome bridges (Fig. 2). 
Based on the results of present cytogenetic studies, the correlation within the chemical determination of pesticides in examined samples was assessed. A direct correlation was established between the frequency of micronuclei in interphase cells and the total content of organochlorine pesticides in natural water samples -0.96 and soil specimens -0.74 .

Genotoxic substance research is of great importance for the protection of the environment because it enables an insight into the influence of genotoxic substances on organisms. With the Allium-test and related genotoxic tests one can determine the influence of chemical substances on an organism [5].

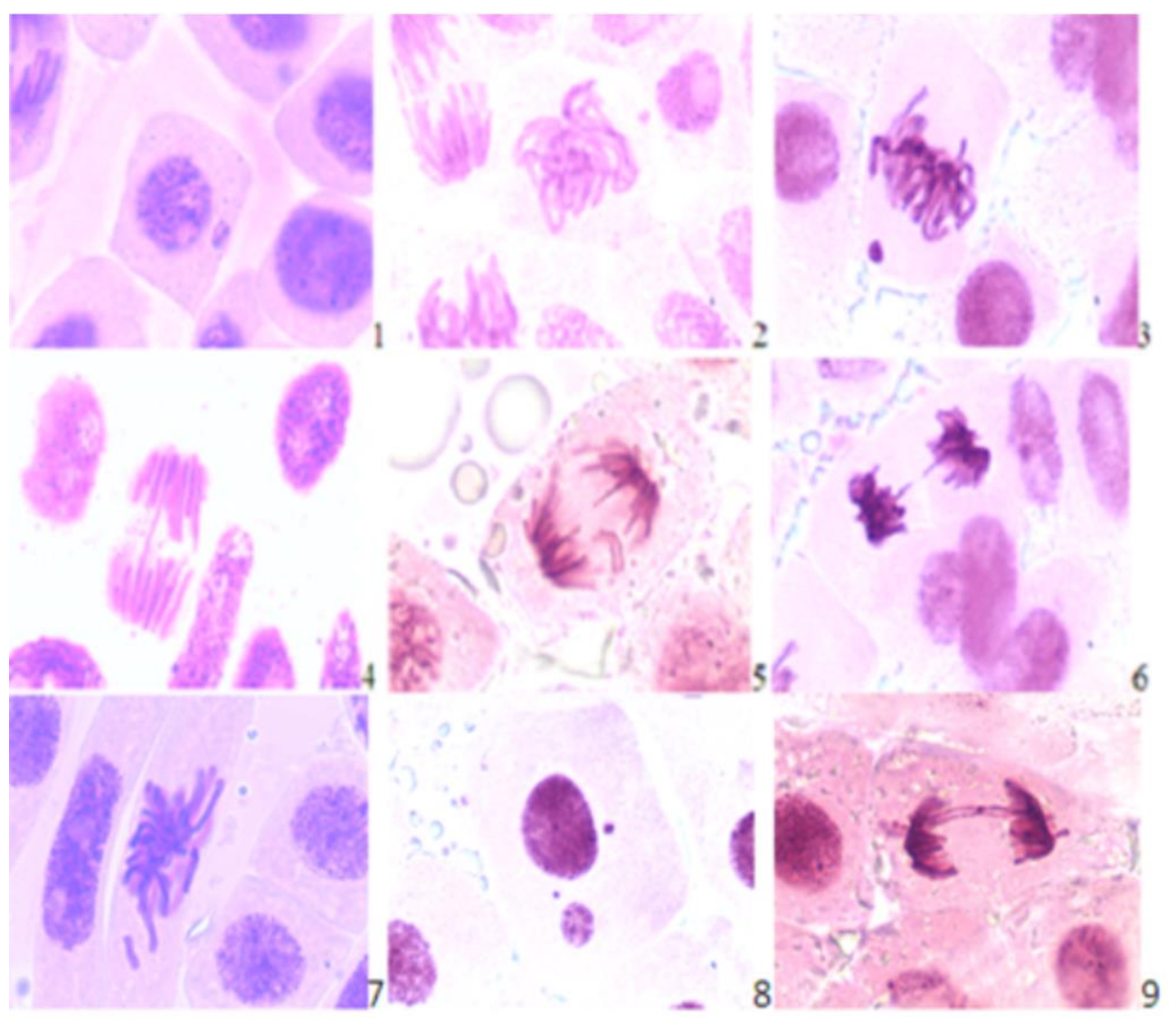

Fig. 2. Types of cytogenetic disorders during the Allium test.

1 - micronucleus in interphase; 2-micronucleus in prophase; 3- micronucleus in metaphase; 4chromosome bridge in anaphase; 5 - backward chromosomes in anaphase; 6-chromosome bridge in telophase; 7 - C-metaphase with a fallen chromosome; 8 - interphase cell with three micronuclei of different sizes; 9 - anaphase with two bridges.

Pesticides have been widely tested in bioassays with plants and positive results have generally been obtained. In a study to evaluate the negative effects of diuron, a substituted urea herbicide [6] reported cytotoxic and genotoxic effects in A. cepa meristematic cells. The authors showed that diuron causes mitotic alterations by inhibiting the polymerization of the tubulin subunits of microtubules. In a study to evaluate the action of the trifluralin herbicide in A. cepa test system [7], showed the mechanism of $\mathrm{MN}$ formation by polyploidization of the genetic material. A study to evaluate the genotoxic effects of the herbicides pentachlorophenol and butachlor by the A. cepa test showed magnification CA values for all 
the chemicals tested [8]. Also the genotoxicity of roundup [9], atrazine [10], insecticides (cypermethrin, fenvalerate) [11], deltamethrin [12] and many others has been shown. Moreover, many of them are also characterized as clastogenic and aneugenic agents. Thus, the many authors concluded that pesticides can induce cytotoxic and genotoxic effects on the A. cepa test system, which showed to be sensitive to this analysis [13].

Studies of sensitivity and correlation among test systems are fundamental for a more accurate evaluation of the environmental risks, as well as extrapolation of data to other target organisms, e.g. man. Tests to detect the risks to human health are conducted using several test systems which use a wide variety of organisms. Allium-test shows a good correlation with similar tests applied on mammals and other vertebrates [13]. According to Grant, of 148 chemicals evaluated by the Allium test, $76 \%$ presented positive results [14]. Fiskesjo reported that the sensitivity of the A. cepa test was virtually the same as the one observed for algae and human lymphocyte test systems [15]. Rank and Nielsen showed a correlation of $82 \%$ of the A. cepa test in relation to the carcinogenicity test in rodents [16].

In our study, in addition to the Allium-test system, we also used a test system - cultures of human lymphocytes and mouse-like rodents (micronuclear test and comet-test) that live in the studied villages. All these tests showed a similar degree of pollution of villages, according to a chemical analysis of soils and natural water. A small correlation at 0.50 was shown only between the comet-test in mouse rodents and the Allium-test results in the study of natural water in the studied villages. Some authors believe that this non-correlation may be related to the enzymatic activities of the detoxification process of exogenous substances and DNA repair, which are less relevant in plant cells than in mammals [17].

\section{Conclusions}

Around the territories of the former warehouses of obsolete and prohibited pesticides, an elevated level of organochlorine compounds remains, significantly exceeding the MPC. The main pollutants are highly toxic compounds - DDT and DDE. Using Allium-test, an increased level of cytogenetic disorders in the root meristematic cells was found, which correlated with the total content of organochlorine pesticides. Nonetheless, we can say that using different test systems is important for a more comprehensive assessment of the different aspects of an agent action, thus obtaining a complete overview of its hazard.

The work was performed under Scientific and Technical Program: No. BR05236379 «Comprehensive assessment of unutilized and banned pesticides impact on genetic status and health of population of Almaty region»

\section{References}

1. A. Nurzhanova, S.Kalugin, K. Zhambakin, Environ Sci Pollut Res., 20(4), 2054-2063 (2013)

2. P. Firbas, T. Amon, J. Bioremed. Biodeg., 4(4), 2-5 (2013)

3. T.H. Ma, Mutat Res, 426, 103-106 (1999)

4. K. al-Sabti, Cytobios, 58 71-78 (1989)

5. P. Firbas, T. Amon, Caryologia, 67(1), 25-35 (2014)

6. L.K.S. Chauhan, P.N. Saxena, V. Sundararaman, S.K. Gupta, Pest. Biochem. Physiol., 62, 152-163 (1998)

7. T.C.C. Fernandes, D.E.C. Mazzeo, M.A. Marin-Morales, Pest. Biochem. Physiol., 88, 252-259 (2007)

8. B. Ateeq, M. Adul Farrah, M.N. Ali, W. Ahmad, Mutat. Res., 514,05-113 (2002) 
9. J. Rank, A.-G. Jensen, B. Skov, L.H. Pedersen, K. Jensen, Mutat. Res., 300, 29-36 (1993)

10. P. Bolle, S. Mastrangelo, P. Tucci, M.G. Evandri, Environ. Mol. Mutagen., 43, 137141 (2004)

11. L.K.S. Chauhan, P.N. Saxena, S.K. Gupta, Environ. Exp. Bot. 42 181-189 (1999)

12. L.K.S. Chauhan, S.K. Gupta, Pest. Biochem. Physiol. 82, 27-35 (2005)

13. D.M. Leme, M.A. Marin-Morales. Mutation Research.682, 71-81 (2009)

14. W.F. Grant, Mutat. Res. 99, 273-291 (1982)

15. G. Fiskesjo, Hereditas. 102, 99-112 (1985)

16. J. Rank, M.H. Nielsen, Mutat. Res. 312, 17-24 (1994)

17. D. Feretti, I. Zerbini, E. Ceretti, M. Villlarini, C. Zani, M. Moretti, C. Fatigoni, G.Orizio, F. Donato, S. Monarca, Water Res. 42, 4075-4082 (2008) 